\title{
LA MONSTRUOSIDAD FEMENINA EN LAS NARRADORAS FANTÁSTICAS ESPAÑOLAS DEL SIGLO XXI ${ }^{1}$
}

\author{
FEMALE MONSTRUOSITY IN SPANISH FANTASTIC WOMEN \\ NARRATORS OF THE $21^{\text {st }}$ CENTURY
}

\author{
David ROAS \\ Universitat Autònoma de Barcelona \\ david.roas@gmail.com
}

\begin{abstract}
Resumen: El monstruo sigue siendo una figura esencial en la ficción fantástica, adaptándose a los nuevos miedos y deseos que se desarrollan en el seno de la cultura posmoderna. En las páginas que siguen voy a explorar algunas de las formas más renovadoras que toma la monstruosidad fantástica femenina en la obra de las narradoras españolas del siglo XXI: la madre monstruo, la experiencia de la maternidad como conflicto y la niña monstruo. Tres encarnaciones que demuestran no solo la pervivencia y funcionalidad del monstruo en la ficción fantástica actual de autoría femenina, sino su reactualización con el objetivo de denunciar los condicionantes culturales, sociales y políticos impuestos sobre la mujer, específicamente en lo referido a la experiencia de la maternidad, las estructuras familiares y el mundo infantil.
\end{abstract}

Palabras clave: Monstruosidad femenina. Fantástico. Narrativa española. Feminismo.

Abstract: The monster remains an essential figure in fantastic fiction, adapting to the new fears and desires that develop within postmodern culture. In the pages that follow, I am going to explore some of the most innovative forms that the female fantastic monstrosity takes in the work of $21^{\text {st }}$ Century Spanish female narrators: the monster mother, the experience of motherhood like conflict, and the monster girl. Three incarnations that show not only the survival and functionality of the monster in current fantastic fiction of female authorship, but its updating with the aim of denouncing the cultural, social and political conditioning factors imposed on women, specifically in relation to the experience of the motherhood, family structures and the world of children.

Keywords: Female monstrosity. Fantastic. Spanish Narrative. Feminism.

\footnotetext{
${ }^{1}$ This work is partially supported by ICREA under the ICREA Academia programme. También es resultado del proyecto de investigación Lo fantástico en la cultura española contemporánea (1955-2017): narrativa, teatro, cine, televisión, cómic y radio, del Ministerio de Economía, Industria y Competitividad (FFI201784402-P, I.P. Dr. David Roas).
} 


\section{BREVES CONSIDERACIONES SOBRE EL MONSTRUO FANTÁSTICO}

Lo fantástico nos sitúa dentro de los límites del mundo que conocemos para quebrantarlo con un fenómeno que por su dimensión imposible altera la manera natural y habitual en que ocurren los hechos en ese espacio cotidiano (Roas, 2011). Porque el objetivo de lo fantástico es desestabilizar los códigos que hemos trazado para comprender y representar lo real, una transgresión que al mismo tiempo provoca el extrañamiento de la realidad, que deja de ser familiar y se convierte en algo amenazador.

El monstruo encarna en sí mismo esa dimensión transgresora: su existencia subvierte los límites que determinan lo que resulta aceptable desde un punto de vista físico, biológico e incluso moral. Y por ello supone siempre una amenaza, porque —además de representar (y provocar) nuestros miedos - problematiza nuestros códigos cognitivos y hermenéuticos:

los monstruos son antinaturales en relación con un esquema conceptual cultural de la naturaleza. No encajan en el esquema; lo violan. Así, los monstruos no solo son físicamente amenazadores; también lo son cognitivamente. Amenazan el conocimiento común (Carroll, 2005: 86).

De ahí, como decía, su inevitable relación con el miedo: el monstruo metaforiza nuestros atávicos miedos a la muerte (y a los seres que transgreden el tabú de la muerte, como ocurre con el vampiro, el fantasma, el zombi y otros revenants), a lo desconocido, al depredador, a lo materialmente espantoso... Pero, al mismo tiempo, el monstruo nos pone en contacto con el lado oscuro del ser humano al reflejar nuestros deseos más ocultos, revela el Hyde que todos llevamos dentro y que se alimenta tanto de nuestros miedos como de nuestro (casi) irrefrenable deseo de transgresión:

En la medida en que el monstruo es espejo cóncavo de la condición humana, su utilidad para el desciframiento de quiénes y cómo somos es incuestionable. El monstruo muestra y demuestra [...] El monstruo es por excelencia la objetivación de la angustia, quizá el más elocuente miedo derivado de ese abismo originario en el cual palpitan, indistinguibles, el horror y el deseo, el vértigo de la libertad y hasta el miedo que en nosotros provoca descubrir cuánto deseamos lo espantoso (Padilla, 2013: 82).

Todo ello implica, además, que el monstruo evolucione, que sea plural y proteico: a la vez que se mantienen ciertas constantes transhistóricas esenciales, el monstruo cambia, se adapta al momento histórico y al contexto cultural, a los miedos y ansiedades de la sociedad que lo produce ${ }^{2}$. Y ello también exige emplear nuevos recursos, técnicas

\footnotetext{
${ }^{2}$ A este respecto, Cohen afirma que los monstruos deben "be examinated within the intricate matrix of relations (social, cultural, and literal-historical) that generate them" (1996: 5). Idea que, entre otros, corrobora Hock-Soon: "Monsters are always, in different degrees, the product of cultural, social and historical anxieties" (2004: 5).
} 
diferentes, más sutiles, para comunicar tales miedos, para despertarlos o reactivarlos, y, con ello, causar la inquietud del receptor.

Uno de estos nuevos recursos, recurrentes en la ficción fantástica posmoderna, es convertir al monstruo en el narrador de su historia (Campra, 1991; Roas, 2011 y 2019). De ese modo, nos hace partícipes de sus experiencias y temores ante su identidad monstruosa - contra la que, además, en muchas ocasiones se rebela - y su relación con los humanos. El monstruo se humaniza y, en cierto modo, atenúa su otredad. Hollinger (1997: 199-200) relaciona ese nuevo recurso con el proceso de descentramiento que caracteriza a la Posmodernidad, "for example, voices historically relegated to the margins of discourse, of representation, of authority have to come to the foreground, and perspectives rarely before privileged have begun to be considered as -at least potentially_ valid". Un proceso de descentramiento también vinculado a una mayor conciencia — positiva - de la alteridad y la diferencia.

Otro de esos aspectos a destacar es el hecho de que la ficción posmoderna acude en muchas ocasiones a la combinación de lo fantástico y el humor para dar nueva vida a recursos, temas y tópicos sobreexplotados en la ficción fantástica (Roas, 2014; Boccuti, 2018). El escepticismo posmoderno ante la idea de una realidad estable y ordenada propia del siglo XIX, permite introducir esa distancia irónica y abre la puerta para que lo fantástico pueda combinarse con el humor como vía de subversión e impugnación de nuestra idea de realidad (incluido el propio ser humano). Aunque hay que tener en cuenta un aspecto esencial: los relatos fantásticos a los que me refiero no están construidos para provocar la carcajada, lo que supondría la anulación del efecto inquietante en beneficio de lo cómico. Lo que sus autores y autoras hacen es combinar lo fantástico con la ironía y la parodia para potenciar el efecto distorsionador de sus relatos, sin que, por ello, los fenómenos narrados pierdan su condición de imposibles. Como advierte Linda Hutcheon en $A$ Theory of Parody (1985), la parodia ha dejado de ser un fenómeno vinculado a la intención del autor y a la inscripción de una serie de señales en el texto, para convertirse en una actitud de lectura, una forma desenfadada y autoconsciente de enfrentarse a ciertas manifestaciones culturales. Como decía, la perspectiva paródica permite el distanciamiento de la realidad necesario para la expresión del escepticismo posmoderno (Hutcheon, 1988). De ese modo, la ironía y la parodia permiten a los escritores explorar nuevas vías de expresión para lo fantástico, nuevas formas de llevar a cabo una (siempre) necesaria actualización de sus motivos y convenciones. En el caso específico del monstruo, su tratamiento irónico y/o paródico implica una reactualización de sus formas y funciones clásicas sin que ello implique la pérdida de su dimensión inquietante: siguen siendo — como después veremos en algunos de los ejemplos que voy a comentar- seres imposibles, que, por ello, suponen una transgresión de nuestras convicciones sobre lo real. 


\section{FEMINISMO, FANTÁSTICO Y REACTUALIZACIÓN DEL MONSTRUO}

Lo fantástico - y no me refiero solo a la literatura española — ofrece también nuevas maneras de pensar (y representar) lo femenino, que, como vamos a ver, implica también la reactualización de tópicos centrales en dicha categoría, entre ellos el monstruo.

Así, entre las escritoras actuales cada vez es más visible un uso feminista de lo fantástico caracterizado por la recurrencia de tres aspectos esenciales: 1) una cosmología de temas específicamente vinculados a la experiencia femenina; 2) las voces narradoras femeninas, para exponer en primera persona la experiencia de lo fantástico; y 3) la presencia de mujeres como agentes de la acción: sus historias traducen un constante movimiento de reconstrucción identitaria frente a la identidad estereotipada construida por la heterodesignación del discurso hegemónico patriarcal, lo que, a la vez, implica la inversión de los roles atribuidos a la mujer (con la consiguiente deconstrucción de esos estereotipos) y la destacada presencia de la monstruosidad femenina como forma de denuncia y transgresión de los modelos tradicionales, tanto en lo referente a la representación del cuerpo como a los límites de la monstruosidad y, sobre todo, a la violencia y el horror como reflejo de la opresión sobre la mujer (Roas, 2020).

Tiene razón Cortés, cuando afirma que "la existencia de monstruos femeninos dice más de los miedos masculinos (entre otras cosas porque han sido los hombres quienes los han creado) que sobre los deseos de la mujer o la subjetividad femenina" (1997: 41). Ello ha determinado que muchos trabajos esenciales sobre la monstruosidad femenina, como los de Dijkstra (1986), Bornay (1990), Creed (1993) y Pedraza (1991), (1998), (2004) y (2014), se hayan centrado en la obra de autores masculinos para evidenciar la dimensión misógina de las diversas representaciones de las mujeres monstruo, tanto naturales como fantásticas. Así, por ejemplo, Creed (1993), advierte que tales representaciones no son otra cosa que la expresión del miedo de los hombres hacia la mujer, sobre todo en épocas en las que esta empieza a liberarse de los roles diseñados por el poder patriarcal. De ese modo, la monstruosidad femenina también va a emplearse como manifestación de la rebelión contra dicho poder. Basta pensar, por ejemplo, en la bruja y la vampira (o, fuera del estricto campo de lo fantástico, en la loca, la mujer salvaje o la femme fatale), figuras evaluadas tradicionalmente como seres abyectos (Kristeva, 1988) y, por ello, amenazantes para el hombre, que se han ido convirtiendo progresivamente en representaciones de la mujer que cuestiona el orden establecido y que suele contravenir - no en todos los casos - el canon de belleza imperante en la sociedad occidental (el cuerpo deviene en sí mismo objeto monstruoso). Algo que, como veremos enseguida, se manifiesta de un modo mucho más evidente - y recurrente - en la ficción fantástica y terrorífica creada por mujeres ${ }^{3}$. Ello aparece explicitado, por ejemplo, en el prólogo de la antología Monstruosas (2019), en la que se recoge una colección de cuentos de escritoras

\footnotetext{
${ }^{3}$ Véanse al respecto Santos (2016), la tesis doctoral de Andrea Abalia (2013), dedicada al análisis de lo siniestro femenino en la creación plástica contemporánea, así como la bibliografía específica que cito en los diversos apartados de este artículo.
} 
españolas del siglo XXI que buscan ofrecer nuevas perspectivas de monstruas provenientes de diversas tradiciones culturales. Así, tal y como afirma Sangre Fucsia en el prólogo, "las monstruas se reivindican como las portadoras de ese otro discurso que nos permite construirnos a partir de lo abyecto y la rebelión" (2019: 12) y se advierte que el objetivo de la antología es el cuestionamiento del poder y el orden establecido y la voluntad de liberar esos arquetipos femeninos (las monstruas) de sus obvias metáforas patriarcales (2019: 12). Una intención que coincide, por citar solo otro ejemplo más, con la de la antología Vuelo de brujas (2018), editada por Gemma Solsona Asensio, en la que participan autoras españolas e hispanoamericanas actuales. En el prólogo, firmado por La Nave Invisible, se reflexiona sobre la concepción tradicional de la bruja y cómo ha llegado a nuestros días "mantenida por una visión eminentemente masculina y patriarcal, de modo que el término bruja se sigue utilizando con connotaciones peyorativas tanto para calificar a mujeres que actúan con dudosa moral como para definir a aquellas que buscan su libertad y la descosificación de sus cuerpos" (2018: 12). A ello se añade, para evidenciar el objetivo de la antología, cómo el feminismo "reivindica la bruja como la imagen de la mujer emancipada, con la intención de reapropiarse el término y desproveerlo de los siglos de misoginia que lleva a sus espaldas" (2018: 12-13).

En las páginas que siguen voy a explorar algunas de las formas más renovadoras que toma la monstruosidad fantástica femenina en la obra de las narradoras españolas del siglo $\mathrm{XXI}^{4}$ : la madre monstruo, la experiencia de la maternidad como conflicto y la niña monstruo. Tres encarnaciones que surgen del estricto ámbito cotidiano y familiar y que, hasta la fecha, han sido muy poco estudiadas en relación a la narrativa fantástica española.

\subsection{Maternidades monstruosas}

La maternidad se ha convertido en un tema central de la ficción contemporánea, sobre todo a través de la crítica del control que se ejerce sobre dicha experiencia por parte del poder heteropatriarcal ${ }^{5}$ :

\footnotetext{
${ }^{4}$ El trabajo que aquí presento es una primera aproximación parcial al tema, que, además, forma parte de una investigación de mayor calado y dimensión comparatista centrada en las creadoras fantásticas españolas del siglo XXI en narrativa, teatro, cine, TV y cómic. Ello justifica que las conclusiones aportadas en este trabajo son todavía escasas y superficiales, a falta de completar el análisis de estas (y otras) manifestaciones de la monstruosidad femenina en un mayor número de narradoras españolas actuales, datos que además deberán combinarse con el análisis de la obra de las creadoras fantásticas teatrales, audiovisuales y gráficas. Asimismo, debo advertir que, al tratarse de autoras que inician su obra a partir de 2000, he de dejado fuera de mi análisis a autoras todavía en activo pero que empezaron a publicar en décadas anteriores, como, por ejemplo, Cristina Fernández Cubas y Pilar Pedraza, con las que las narradoras actuales comparten varios de los rasgos ya expuestos, además de la importante presencia que tiene el monstruo - fantástico y natural- en sus obras.

${ }^{5}$ A este respecto cabe señalar que los estudios sobre las literaturas latinoamericanas han prestado en estos últimos años una especial atención a la presencia y sentidos de la maternidad en la ficción. Entre otros muchos, cabría destacar aquí Domínguez (2007), Noguerol (2013) o Amaro (2020), aunque debo advertir que no abordan el estudio de dicho tema en la narrativa fantástica, por lo que no les he utilizado en mis análisis.
} 
La maternidad no es un "hecho natural", sino una construcción cultural multideterminada, definida y organizada por normas que se desprenden de las necesidades de un grupo social específico y de una época definida de su historia. Se trata de un fenómeno compuesto por discursos y prácticas sociales que conforman un imaginario complejo y poderoso que es, a la vez, fuente y efecto del género. Este imaginario tiene actualmente, como piezas centrales, dos elementos que lo sostienen y a los que parecen atribuírsele, generalmente, un valor de esencia: el instinto materno y el amor maternal (Badinter, 1980 y Knibiehler, 2000). [...] cualquier fenómeno que parezca contradecir la existencia de los elementos mencionados, es silenciado o calificado como "anormal", "desviado" o "enfermo" (Palomar, 2005: 36) .

Ello lleva a las autoras a mostrar cómo se vive la maternidad en primera persona y en cuerpo propio frente a las presiones del imaginario patriarcal (y los roles impuestos por este), a través de una figura cada vez más recurrente en la ficción tanto realista como fantástica: la "mala madre" (Palomar, 2004; Arnold, 2013), es decir, la mujer que subvierte la idea normativa de maternidad, basada en el instinto materno, el sacrificio y la entrega gozosa al cuidado de los hijos. Un evidente conflicto entre biología y cultura que implica el desajuste entre las creencias y valores heteronormativos (y su efecto normalizador, represor) y la experiencia de la maternidad, que no tiene por qué responder a tales valores, lo que implica, a su vez, un cuestionamiento del estamento familiar: "The Bad Mother can point to dissatisfaction and disillusionment with the psychosocial structures of the family" (Arnold, 2013: 69).

Las narradoras fantásticas españolas actuales exploran la figura de la "mala madre" por dos vías mutuamente interrelacionadas ${ }^{7}$ : la maternidad como experiencia monstruosa; y la madre como monstruo fantástico, lo que la convierte en una amenaza para sus hijos, $\mathrm{y}$, de ese modo, en la forma más extrema de la "mala madre".

\subsubsection{La maternidad como experiencia monstruosa}

En la obra de las autoras actuales son recurrentes los cuentos cuyas protagonistas exploran una visión de la maternidad en conflicto con los roles sociales atribuidos (impuestos) a dicha experiencia, lo que las convierte, como decía, en "malas madres" y, por eso mismo, en monstruas, normalmente de carácter metafórico, pero también a veces literales, a ojos de los demás e incluso para ellas mismas.

\footnotetext{
${ }^{6}$ Véanse también, entre otros, Badinter (1980), Donath (2017) y Recalcati (2018). Junto a estos trabajos, podrían citarse también aquí estudios ya clásicos (por lo que he preferido no detenerme en ellos) sobre la institucionalización de la maternidad como el de Rich (1976), quien propuso una distinción esencial entre dos significados superpuestos de maternidad: la relación potencial de cualquier mujer con su capacidad de reproducción y con los hijos; y la institución, cuyo objetivo es asegurar que este potencial —y todas las mujeres - permanezcan bajo el control masculino (1976: 47). Véanse también otros textos también clásicos sobre el uso de la violencia, política y simbólica, en el cuerpo femenino, como son los de Irigaray (2007 [1974]), Butler (1993) o Federici (2007).

${ }^{7}$ Acerca de la maternidad monstruosa en la ficción fantástica y terrorífica, véanse Ussher (2006), Arnold (2013) y Renner (2015).
} 
Para ejemplificar esta variante he seleccionado los cuentos "True Milk" (2015), de Aixa de la Cruz, y "El instinto" (2017), de Mónica Crespo, dos textos en los que se reúnen esos aspectos que acabo de mencionar, así como otro de los miedos maternos esenciales (también vinculados simbólicamente al miedo a convertirse en "malas madres"): la posibilidad de parir un monstruo o, al menos, un ser de aspecto anormal. Algo que ya habíamos visto representado en la ficción fantástica y/o terrorífica creada por hombres a través de historias en las que la amenaza proviene del vientre de la mujer ${ }^{8}$. Basta pensar en dos películas tan influyentes como The Village of the Damned (1960, Wolf Rilla) y Rosemary's Baby (1968, Roman Polanski) ${ }^{9}$. En la primera de ellas se narra cómo las mujeres de una misma localidad — tras caer inconscientes todos los habitantes del pueblo, animales incluidos - se embarazan el mismo día (conforme avanza la película sabremos que la fecundación es de origen alienígena) y dan a luz niños con un mismo aspecto (rubios, ojos azules), que, encima, crecen muy rápido, tienes poderes paranormales y actúan como un único ser. Todos ellos serán convenientemente destruidos gracias, como es habitual, al sacrificio de un hombre. Por su parte, Rosemary's Baby, tal y como desvelaba el título español de la película (La semilla del diablo), gira en torno al embarazo de la protagonista a manos del demonio con el fin de traer su hijo a la tierra, temática que después explotarán otras muchas películas, como la célebre The Omen (1976, Richard Donner), cuyo protagonista, Damien, es también una perfecta encarnación del niño monstruo, al que luego me referiré.

Frente a la amenaza cataclísmica que supone tanto una invasión alienígena como la llegada del anticristo, las autoras que he seleccionado optan por dar a sus historias fantásticas una dimensión mucho más cotidiana para proponer una inquietante reflexión sobre el instinto materno y los vínculos con el hijo monstruo. Por ello resulta muy revelador que en los dos cuentos seleccionados las madres protagonistas se sacrifiquen (en "True Milk" dando su propia sangre) por el desarrollo de sus hijos, aunque también es muy significativo que los dos finales — abiertos - anuncien la posible destrucción de los monstruos y, con ello, la "solución" del problema que estos generan con su existencia

\footnotetext{
${ }^{8}$ No hace falta insistir aquí en el temor masculino a la posibilidad de que la mujer pueda engendrar monstruos (Cortés, 1997: 41), vinculado, a su vez, a los "peligros" que conllevaba la libre sexualidad femenina no orientada a la procreación (Muchembled, 2002: 102), sobre los que reflexionaron muchos tratadistas clásicos. De ese modo, los excesos amorosos o el hecho de mantener relaciones durante la menstruación (como refiere, por ejemplo, Ambroise Paré en su célebre Des monstres et prodiges, 1575), podían provocar el nacimiento de monstruos. Sugiero la lectura de Rosi Braidotti, "Mothers, Monsters, Machines", en The Nomadic Subjects (1994).

${ }^{9}$ Como se comprobará en el resto de apartados de este artículo, he optado por incluir numerosos ejemplos cinematográficos como introducción a las diversas variables de los monstruos femeninos que analizo, dada la enorme influencia que estas películas han tenido sobre creadores/as y lectores/as en relación a la representación iconográfica de tales monstruos y a su empleo en la ficción fantástica y terrorífica. Y dado que, además, me centro en autoras del siglo XXI, he optado por no detenerme en trazar una genealogía de la monstruosidad femenina desde la mitología y la literatura clásica ni acudir a textos no encuadrables dentro de la categoría de lo fantástico (todo ello ya muy bien estudiado en los trabajos que cito a lo largo del artículo). Ello también explica dejar fuera de estas páginas otros precedentes esenciales sobre la monstruosidad de autoría femenina, pero en los que el monstruo no se encarna en una mujer (basta pensar en el Frankenstein de Mary Shelley).
} 
y, sobre todo, su alimentación. También merece destacarse, como veremos, el hecho de que los padres estén prácticamente ausentes, lo que, sin embargo, no les impide, en sus escasas intervenciones, cuestionar la adecuación de sus mujeres a las normas que rigen la "buena" maternidad.

El cuento de Aixa de la Cruz propone, además, una sobrecogedora e irónica revisión del mito del vampiro (encarnado en un bebé), de ahí el juego intertextual entre el título del cuento y el de la serie de TV True Blood. Como también ocurre en el relato de Mónica Crespo, la madre protagonista no tiene una dimensión fantástica en sí misma (es un ser natural), pero la adquiere por el propio hecho imposible de dar a luz a un monstruo sediento de sangre.

"True Milk" relata en primera persona los agobios de la protagonista ante su nueva situación como madre, tras una poco positiva experiencia con el embarazo y el maltrato durante y después del parto ${ }^{10}$ a manos del estamento médico, su marido y su suegra, tres instancias del poder patriarcal que actuarán al unísono para cuestionarla como madre. El cuento se centra en los problemas para alimentar a su hijo.

Tras sus fallidos intentos de amamantarlo (que achaca tanto a su inexperiencia como a la tensión que le generan las reconvenciones de su suegra), la protagonista llega incluso a dudar de ese instinto materno que (supuestamente) debería sentir:

Me quedé mirando al nene, contorsionado, ronco, la piel arrugada, todo él de un material extraño. No parecíamos de la misma especie. ¿Dónde estaba mi instinto maternal? Me habían dicho que era algo instantáneo, biológico, inevitable, un resorte químico que se dispara durante el parto. Aunque también me habían dicho otras cosas: que no debía ser madre; que era muy joven; que [...] era legal abortar (2015: 42-43).

Con el paso de los días se hace evidente que el niño no está sano, pues apenas come, lo que la llena de inquietud. Y en otro de sus intentos de darle de mamar, el bebé le muerde salvajemente el pezón:

Di un grito. Lo aparté de mí. Grité de nuevo: manaba sangre de su boca. Se relamía. En el cerco oscuro de mi pezón se habían abierto dos llagas diminutas. El bebé hacía muecas torpes para acercarse de nuevo a la fuente de comida, pero yo no veía que hubiera brotado una sola gota de leche. Le devolví a su cuna y comenzó a llorar histérico (2015: 45).

Entonces espera a quedarse sola y se hace un corte en la mano:

Nunca pensé que fuera capaz de autolesionarme, pero obré con mucha decisión. Después de todo era la peor madre del mundo; algo tenía que hacer para expiar mi culpa. Brotó sangre abundante y la dejé caer en un bol. Me drené hasta marearme. Luego la mezclé con leche en polvo. [...] no sabía si era ético lo que estaba haciendo; sabía que Dios condena el vampirismo [...] hay una relación directa entre las cosas que nos provocan asco y las cosas que Dios condena, como la zoofilia, el canibalismo, el incesto o la

${ }^{10}$ Un parto que, encima, fue por cesárea, lo que también la hace sentirse fracasada. 
homosexualidad. Pero los hechos son, y que Dios me perdone, que aquel biberón de color chicle fue el primero que mi bebé engulló con apetito desde su nacimiento (2015: 46).

A partir de ese momento, el niño mejora muy deprisa, pues sigue alimentándolo con sangre, sin que nadie descubra sus heridas, ni siquiera su marido: ante el asco que a este le dan las cicatrices de la cesárea, ella siempre apaga la luz antes de desnudarse (lo que también nos ofrece un interesante retrato de la relación de pareja tras el parto).

Todo se desquicia el día en que la protagonista, tras desmayarse de debilidad, se clava un cristal en el hombro y empieza a sangrar abundantemente. Entonces, el bebé - desde su habitación - empieza a llorar "con una ansiedad insólita" y se da cuenta de que es su sangre lo que lo excita. Asustada, cierra con llave la habitación del niño (dejándolo dentro) y se marcha corriendo de casa.

Tras pasar unas horas en un bar (tomando, irónicamente, unos tequilas con sangrita), la protagonista revisa su móvil y comprueba que tiene diez llamadas perdidas de su marido y su suegra. Entonces piensa en lo que pueden haber encontrado al llegar a casa y decide regresar. El cuento se cierra con una irónica reflexión de la protagonista sobre maternidad y vampirismo:

Lo primero que vi fue una ambulancia en el jardín. Si algo fatal había ocurrido, si era ya cadáver lo que transportaban al interior del furgón, solo deseé que se tratara del niño. Después de todo, a él le aguardaba la eternidad, como a cualquier miembro de su especie (2015: 48-49).

Mónica Crespo va aún más lejos en su cuento "El instinto", cuyo inicio es semejante al de "True Milk": la narradora relata el dolor que siente al darle el pecho a su hija, pero añade que no deja de hacerlo "porque creía que era lo mejor para ella" (2017: 13), imponiéndose, de ese modo, su instinto maternal (el cuento va a jugar constantemente con la presión que implica el constructo social del instinto materno, así como de otro instinto - muy diferente - que se irá revelando en su hija). Aun sabiendo que la niña todavía no puede tener dientes, revisa su boca, lo que provoca el llanto de la niña y un evidente sentimiento de culpa por ser "una mala madre, una madre tal vez loca, [...] una desequilibrada que maltrata a su criatura" (2017: 13). Ello le lleva a compararse con las "buenas madres" que le rodean, por las que, además, es constantemente juzgada:

Entonces me decía a mí misma que nunca más, que eran cosas mías, que era demencial. Que era el cansancio, el revuelo de hormonas tras el parto, la falta de experiencia. Que era cuestión de tiempo, que llegaría a ser como ellas, como las buenas madres del parque que paseaban sus bebés rollizos (2017: 13).

Pese a sus dudas y miedos, la niña crece sana y hermosa, lo que ella considera su mejor recompensa. Pero todo cambia el día en que le muerde fieramente en el pezón y descubre que hay algo "agazapado, palpitando en ella" (2017: 15). Ese es el primer momento en que la contempla como un monstruo, pero, inevitablemente, su instinto 
materno se impone de nuevo, anteponiendo el bienestar de su hija a su propio dolor (y miedo). Aunque no contará a nadie la terrible experiencia, ni siquiera a su marido, quien siempre está de viaje por razones laborales, pero cuya ausencia y nula implicación en el cuidado de la niña no le impiden censurarla: "me trataba como una madre obsesiva y nerviosa" (2017: 16).

Las cosas se ponen aún peor cuando a la niña empiezan a salirle los dientes, aunque no puede dejar de cuidarla. Y como crece sana, fuerte y alegre, la protagonista empieza a creer que todo lo vivido no ha ocurrido en realidad, que

tan solo habían sido delirios de madre primeriza, angustiada por el cansancio, las ausencias del marido, los llantos nocturnos, las noches en vela y todo el cansancio acumulado que, en ocasiones, nubla la razón y distorsiona el entendimiento, como me había transmitido mi marido de parte de Doña Pilar [su suegra] (2017: 17).

Hasta que un día entra en la cocina y encuentra a su hija devorando un hígado de vaca crudo "con ojos brillantes y satisfacción oscura" (2017: 17). Si bien no hace nada al respecto, la protagonista empieza a pensar con miedo en el futuro, ahora que la niña ya ha probado la sangre. Es entonces cuando comprende por qué su hija nació "con el peso adecuado, sin ningún defecto o deficiencia” (2017: 18), mientras ella había ido perdiendo peso de forma alarmante.

Las últimas páginas narran la inflexible vigilancia a la que somete a su hija cuando la lleva al colegio o cuando juega con sus amigas, para evitar que aflore su peligroso instinto:

A veces, la pillo chuperreteando con fruición los dedos de una amiguita, se echa sobre ella sujetándole la mano con esa fuerza que solo yo conozco, impidiéndole escapar mientras llora desconsolada buscando a su madre. Y yo veo cómo la llama nace y crece en los ojos de mi hija y oigo el sonido de un gorgoteo incesante, que si no corro a detener será imparable (2017: 19).

El relato se cierra una noche en la que la niña va a despertarla (del padre seguimos sin saber nada) y entonces nos cuenta lo que hacen juntas: "como cada noche, salimos a cazar. Ella es quien elige. Yo la guío y trato de contenerla para que pase desapercibida. Cuando sucede miro para otro lado. Ella es otra, Yo soy otra" (2017: 21). Lo terrible es que el temor por su propia seguridad (que ya no siente) ha sido sustituido por el miedo a que llegue el día en que deje de someterse a su instinto materno - "este amor es una pesada carga, un mandato que condena, un dolor sangrante y áspero” (2017: 21) - y acabe matando a su hija, convirtiéndose, así, en la perfecta encarnación de la madre monstruo, lo que nos lleva al siguiente apartado. 


\subsubsection{La madre monstruo}

El tratamiento fantástico de esta figura permite encarnar en un ser literalmente monstruoso la idea de la madre como entidad amenazante y represora para sus hijos (Kristeva, 1988; Creed, 1993), lo que supone la inversión del arquetipo de la madre amorosa y protectora antes comentado.

Patricia Esteban Erlés ofrece un amplio catálogo de madres monstruo - tanto fantásticas como naturales - en su libro de microrrelatos Casa de muñecas (2012), en el que, como plantea Natalia Álvarez Méndez (2019), la autora utiliza lo macabro y lo fantástico para subvertir los roles que se asignan a las mujeres por imposiciones conservadoras, objetivo, por otra parte, común a toda su obra (véase también de la Varga, 2015). Así, respecto al tratamiento específico de la figura de la madre, Álvarez Méndez afirma lo siguiente, reflexión que podríamos aplicar de un modo general al resto de autoras que estoy analizando en este artículo: "mothers render notorious a concept of maternity which transgresses the positive meaning commonly accorded it by society. It can be perceived as implying a trauma and alienation that may provoke a feeling of rejection towards the mother's daughters" (Álvarez Méndez, 2019: 636).

"Dormitorio principal", una de las diversas secciones que componen Casa de muñecas, recoge algunos de los mejores ejemplos de esta temática, como queda de manifiesto en "La niña sin madre":

La niña sin madre reza por las noches, enterrada entre las sábanas frías, castigada a dormir bajo el crucifijo que habían arrancado de su ataúd, justo antes de sellar el nicho. Mamita, yo te quiero mucho, pero por favor, no te me aparezcas (2012: 43).

Como ocurre en este texto, una de las manifestaciones más habituales de la madre monstruo es la de la fantasma ${ }^{11}$, pero también podemos encontrar relatos que apuestan por la figura de la zombi y otras revenants que regresan de la tumba no solo para aterrorizar a sus hijos sino para convertirse en un peligro para ellos.

Eso es lo que ocurre en el cuento de Ana Martínez Castillo "El amor de una madre" (2019). Mediante la combinación de lo fantástico y el humor - recurrente, como dije más arriba, en la obra de muchas de estas autoras-, el cuento ofrece una delirante vuelta de tuerca a la figura del zombi y del tema de las relaciones maternofiliales, manifestada a

\footnotetext{
${ }^{11}$ Una interesante variante de esta figura es la del padre convertido en monstruo fantástico, que — desde una perspectiva diferente - también es utilizada por las autoras españolas (aunque mucho menos cultivada que la figura de la madre monstruo) para cuestionar los valores patriarcales y la idea tradicional de familia. Dado que no es una forma de monstruosidad femenina, no la he incluido en mi análisis, pero los lectores interesados pueden encontrar reveladores ejemplos en los cuentos "Tocados por la divina mano de Dios" (2019), de Ana Martínez Castillo, y "El que murió sin perdón" (2020), de María Zaragoza, cuyas protagonistas acaban vengándose de sus padres, ambos dibujados como seres represores y crueles. Un ejemplo diferente lo tenemos en el relato de Care Santos "Asuntos pendientes" (2009), en el que se ofrece una lectura más comprensiva de dicho monstruo, aunque sin perder su dimensión imposible, en la figura del patético fantasma de ese padre que regresa doce años después de su muerte para arreglar los asuntos pendientes y al que su familia no hace ni caso.
} 
través de la irónica (y brutal) literalización de la idea de madre "devoradora" (Kristeva, 1988).

El protagonista del relato es un tipo ridículo que se va haciendo aún más ridículo gracias a los torpes intentos por justificar el haber asesinado a su madre "en legítima defensa" (2019: 61) tras su regreso de la tumba:

Me ponía nervioso que hubiera vuelto de la tumba. Es que, reconózcanlo, no es lógico. Atenta contra las leyes de la naturaleza y era contraproducente para mi vida social. Yo quería llevar chicas a casa, y ¿cómo podría explicarles el hedor, la presencia de bichos y el aire corrompido que lo llenaba todo? Pero no se confundan. Mi madre me irritaba ya antes de que estuviera muerta. Siempre quejicosa y destemplada. Sin embargo, tengo que confesar que la quería. ¿Qué clase de monstruo es incapaz de querer a una madre? (2019: 61-62).

Aunque, como descubriremos enseguida, esa será la segunda vez que la mate. Tras narrarnos la insoportable convivencia diaria con su madre (se intuye que enferma de Alzheimer), el protagonista refiere cómo la asfixia con una almohada. Lo que no espera es que la pobre mujer se transforme en una zombi, lo que genera nuevos problemas de convivencia, además del horror (y asco) que le provoca, sin dejar, por ello, de reconocer que todavía la quiere (en varias ocasiones la evoca como una mujer dulce y protectora):

Estaba comiéndose un filete de ternera crudo, a mordiscos, chorreando sangre, con un hambre salvaje y demente. Me cagué vivo. Di unos pasos hacia atrás tratando de no hacer ruido. Pero la vieja me vio. O me olió, vete tú a saber. Se puso de pie tambaleante y trató de avanzar hacia mí. Yo corrí a lo largo del pasillo y me encerré en mi cuarto. Atranqué la puerta como pude porque mi madre trataba de entrar. No sé cuánto tiempo estuvo arañando la puerta hasta que se dio por vencida y regresó a la cocina para seguir comiendo (2019: 66-67).

Creí que iba a levantarse para atraparme, pero no. Se quedó ahí observándome con la cara amarillenta y acartonada, la boca y el camisón manchados de comida. Les juro que de alguna manera sus ojos tenían vida. Creo que me reconoció [...] No pude matarla ese día. Llámenme cobarde si quieren, pero no pude hacerlo. Es que... era mi madre (2019: 68).

El cuento llega a su desenlace cuando el protagonista le entrega a su madre un conejillo de indias vivo que le ha comprado ("Quería ver qué pasaba, por puro interés científico", 2019: 68), que esta devora de un modo tan salvaje que se ve impelido a matarla de nuevo:

Toda esa carne cruda masticada a duras penas. Engullida. Vomité un poco más de bilis y, con una resolución que no reconocí como propia, me di la vuelta y fui a buscar el martillo con el que, al fin, pensaba reventarle la cabeza.

Como uno debe hacer con los zombis (2019: 68-69).

El juego final con la ambigüedad es evidente: ¿realmente la madre se convirtió en zombi o todo no es más que una delirante excusa (ante la policía) para justificar su 
asesinato, pues ya no soportaba cuidarla? Más allá de esa ambigüedad, el cuento propone, como decía, una ácida crítica de las relaciones maternofiliales llevadas a una situación límite, así como el tratamiento paródico de la figura del zombi sin que, por ello, este pierda su dimensión fantástica y terrorífica ${ }^{12}$.

\subsection{La niña monstruo}

La infancia ha sido convencionalmente identificada como el ámbito de la inocencia y la vulnerabilidad, y por ello requiere cuidado y protección por parte de los adultos, una idea "inevitably welded to adult nostalgia for the lost realm of purity and simplicity represented by childhood pasts" (Balanzategui, 2018: 12). Aunque no hay que olvidar que, como advierte Eagleton, bajo esa supuesta inocencia e ingenuidad subyace también algo misterioso e inaprehensible, más allá de las normas y los condicionantes del mundo adulto:

los niños son solo unas criaturas a medio socializar de las que, de vez en cuando, se puede esperar conductas bastante salvajes [...] estamos dispuestos a creer toda clase de noticias siniestras referidas a los niños porque nos resultan como una especie de raza medio alienígena incrustada en nuestro seno. Como no trabajan, no está claro para qué sirven. No practican el sexo, aunque no es descartable que también eso se lo estén callando. Tienen la rareza de aquellas cosas que se parecen a nosotros en ciertos aspectos, pero no en otros. No es difícil, entonces, fantasear incluso con la idea de que estén conspirando colectivamente contra nosotros (2010: 9).

Caracterizarlos como monstruos fantásticos no solo convierte a los niños en una amenaza (para los adultos y para otros niños) sino en una inquietante subversión que desestabiliza las estructuras sociales: "hablar de niños monstruosos es hablar del temor a la destrucción de las jerarquías familiares y de las categorías que ordenan el mundo de la infancia y el de los adultos" (González Dinamarca, 2015: 92) ${ }^{13}$.

El cine fantástico y de terror nos ofrece, de nuevo, una larga serie de historias sobre monstruos infantiles, desde clásicos como las ya mencionadas The Village of the Damned (1960, Wolf Rilla) y The Omen (1976, Richard Donner), a las que hay que añadir, entre otras, The Other (1972, Robert Mulligan), ¿Quién puede matar a un niño? (1976, Narciso Ibáñez Serrador) o Children of the corn (1984, Fritz Kiersch; basada en el relato homónimo de Stephen King), así como películas más recientes, entre las que cabe destacar Saint Ange (2004, Pascal Laugier), El orfanato (2007, Juan Antonio Bayona) o The Children (2008, Tom Shankland). Sin embargo, son pocas, en comparación, las que

\footnotetext{
12 Este cuento muestra unas interesantes coincidencias con la película Shaun of the Dead (2004, Edgar Wright), en la que también se mezclan zombis y humor; en una sus escenas más recordadas, el protagonista se enfrenta al doloroso deber de matar a su madre, una amorosa mujer transformada en una peligrosa zombi que amenaza su integridad y la de sus amigos.

${ }^{13}$ En relación a la presencia de los niños en la ficción fantástica y terrorífica (sobre todo en cine), véanse Büssing (1987), Lury (2010), Arnold (2013), Lennard (2015), Renner (2016), Kord (2016), Balanzategui (2018), así como los diversos los trabajos recogidos en Renner (2013) y Bohlman y Moreland (2015).
} 
apuestan por su encarnación específicamente femenina, como ocurre, por ejemplo, en The Exorcist (1973, William Friedkin), The Little Girl Who Lives Down the Lane (1976, Nicolas Gessner), Ruby (1977, Curtis Harrington), Stir of Echoes (1999, David Koepp) y Lat den rätte komma in (Déjame entrar; 2008, Tomas Alfredson), a las que no me resisto a añadir Night of the Living Dead (1968, George A. Romero), por la brutal escena en la que una niña zombi se alimenta de su propia madre, algo que nunca antes había sido mostrado en la pantalla.

Como en los anteriores apartados, aquí solo voy a referirme a la encarnación femenina de la monstruosidad infantil fantástica, que habitualmente suele manifestarse bajo la forma de la aparición fantasmal, la vampira y otros revenants, así como mediante el juego con el motivo del doble. El hecho de que tales figuras monstruosas se encarnen en el cuerpo de una niña intensifica su efecto inquietante, sobre todo cuando actúan de un modo perverso y cruel, pues, como decía, ello contraviene los rasgos que aparentemente definirían al mundo infantil.

A través de la niña monstruo, las narradoras fantásticas exploran diversos temas y motivos, algunos mutuamente interrelacionados, que, a su vez, reflejan esos cambios de perspectiva antes mencionados en el tratamiento del monstruo y lo fantástico en la Posmodernidad: la crueldad infantil, la represión y violencia de los adultos sobre los niños (a menudo por parte de sus propios progenitores), las relaciones tóxicas entre hermanas (motivadas por la envidia o los celos), el desamparo infantil (normalmente manifestado a través de la niña muerta que descubre con horror su nueva condición monstruosa, producto muchas veces de esa violencia adulta antes mencionada), la venganza de la niña monstruo (respecto a la violencia ejercida por los adultos)... Temas y motivos que en muchas ocasiones responden a una clara intención crítica como denuncia de los modelos de conducta, identidad o belleza impuestos sobre las niñas desde el poder patriarcal.

Junto a dichos temas, hay que destacar dos aspectos muy novedosos, también recurrentes en la obra de muchas de estas autoras: la humanización de la niña monstruo (recurso al que me referí más arriba) y el empleo de la perspectiva infantil para narrar las historias, que nos acerca de un modo más fiel a sus emociones (y a su peculiar comprensión, o falta de la misma, de su estado monstruoso) y, al mismo tiempo, resulta perturbador, pues escuchamos por boca infantil la narración de actos y situaciones de gran violencia y crueldad ${ }^{14}$.

Basta acudir de nuevo a Casa de muñecas de Patricia Esteban Erlés para encontrar numerosas muestras de esa visión de la infancia como mundo siniestro y amenazante, sobre todo en su encarnación femenina. Entre las manifestaciones estrictamente fantásticas, merece destacarse "Matando a Alodia" (2012: 169-170) donde lleva a cabo una doble exploración del monstruo encarnándolo en las niñas asesinas (como manifestación extrema del acoso escolar) y en la pobre Alodia, a la que estas ajustician

\footnotetext{
${ }^{14}$ Saliendo del estricto ámbito de la ficción creada por mujeres, Fernando Iwasaki emplea con gran maestría ambos efectos en muchos de los microrrelatos que componen su libro Ajuar funerario (2004).
} 
cada día y que, como ser imposible, regresa a la mañana siguiente para volver a empezar el ciclo.

En otras ocasiones, como dije antes, las niñas monstruo se manifiestan en forma de fantasmas que vienen a trastornar el mundo de los vivos, ya sea aterrorizando a sus familiares (tema también recurrente en Casa de muñecas) o vengándose de los seres que las trataron cruelmente en vida, tal y como refiere, por ejemplo, Ana Martínez Castillo en su cuento "Paciencia" (2019), protagonizado por un asesino de niños cuya historia es narrada focalizando en su conciencia. Lo revelador del cuento aparece en la escena final, en la que el asesino está espiando a la que ha elegido como nueva víctima, y donde asistimos a la venganza contra este por parte de una sobrecogedora niña monstruo:

Perfecta para ser golpeada. Ideal para jugar. [...] La cría era tonta o sorda o las dos cosas a la vez. Había que ir al grano. Puso su mano en el hombro de la muchacha y la notó fría. Helada. “¿Pero qué...?”. La niña se dio la vuelta despacio y su rostro era blanco. Su boca estaba deformada en un rictus imposible. Algo lo miraba desde dentro de unas cuencas sin ojos. El hombre gritó. Dejó caer su navaja. La niña esbozó una sonrisa torcida y el hombre corrió, tropezó, volvió a correr. La niña, canturreando, se agachó para recoger la navaja y avanzó por el camino, hacia lo oscuro, hacia la región de los hombres solos. Porque en el bosque había cosas. Cosas antiguas. Cosas muertas que esperaban. Y hacía mucho que había caído la noche (Martínez Castillo, 2019: 51).

Otra excelente muestra nos la vuelve a ofrecer Patricia Esteban Erlés en su relato "El juego" (2008, 2019), donde explora otra inquietante vía de la crueldad infantil: las relaciones entre hermanas, en este caso con el siempre inquietante añadido de que se trata de gemelas (la extraña afinidad entre este tipo de hermanos ha sido repetidamente explotada por la ficción fantástica y terrorífica). Narrado por Victoria, la niña protagonista, el cuento se centra en la relación que esta mantiene con su gemela muerta, Laurita, quien le obliga a hacer todo tipo de maldades, incluido matar al perro de la familia. Pese a que ella insiste en que la culpa es de Laurita, sus apenados padres no pueden aceptar lo que la niña insiste en contarles (incluso han decidido internarla en un sanatorio suizo):

mi padre no cree una palabra de lo que le digo, y mamá se echa a llorar cuando acuso a Laurita de obligarme a hacer cosas. Claro, ellos no tienen que aguantar el juego de la muertita, si no también harían todo lo que ella les pidiera. Detesto ese juego, mamita querida, le confesé a mi madre la penúltima vez, Laurita es mala y dice que se morirá delante de mí si no obedezco (2019: 91).

El final es realmente sobrecogedor: ante la pregunta de su madre sobre si entiende que su hermana está muerta, Victoria afirma lo siguiente: "no le contesto ni que sí ni que no. Miro a Laurita, que ahora saca la lengua y se lleva el dedo a la altura de la sien, dándole vueltas. Me entra la risa. Sí, claro, muerta, qué sabrá ella" (2019: 95).

Este cuento recuerda inevitablemente a la historia narrada por Thomas Tryon en su novela The Other (1971), más conocida gracias a la adaptación cinematográfica dirigida 
por Robert Mulligan en 1972, en la que se hace creer al lector, durante buena parte de la narración, que la historia está protagonizada por los hermanos gemelos Niles y Holland Perry, hasta que al final se revela que Holland ha muerto tiempo atrás, lo que genera la duda - como en el relato de Esteban Erlés - de si este es una aparición sobrenatural o un delirio de la mente trastornada de Niles a causa del trauma provocado por la muerte de su hermano.

La relación fantasmal entre hermanas aparece también en el cuento "Elvira" (2019), de Ana Martínez Castillo, esta vez narrado por una voz externa, aunque adoptando la perspectiva de Enriqueta, la niña protagonista, a fin de reflejar lo más fielmente posible el modo en que esta vive la terrible experiencia de ver a su hermana muerta, la Elvira del título, y a otros muchos seres fantasmales que la acompañan - y atormentan — desde que era un bebé.

Elvira empezó a aparecerse justo al día siguiente de su muerte y - a diferencia de lo que ocurre en "El juego" de Esteban Erlés - no hay en ella y en sus acciones nada divertido: "Huele a cera, a esas velas que se ponen para Todos los Santos. Se acerca a su cama y se tumba a su lado, y ella se queda muy quieta, casi sin respirar, hasta que Elvira por fin se va" (2019: 55). Además, no deja de insistirle — sin mover los labios, mirándola con sus ojos vacíos - "que se tiene que ir con ella porque donde está apenas hay niños. Dice que va a ir todas las noches porque es su hermana y la echa de menos" (2019: 55).

Con el tiempo, Enriqueta enferma gravemente y deduce que va a morir, "porque todos los niños al final se mueren" (2019: 57), como también lo hicieron su hermano Miguel, justo después de nacer, o la prima Aurora, "de una enfermedad como la suya" (2019: 57). Niños fantasmales que, al llamado de Elvira, se agrupan ahora junto a su cama, contentos porque "Se van a ir todos juntos pronto" (2019: 57):

Y Enriqueta no puede contarle a nadie que Elvira le da miedo, que la habitación entera huele a cera aunque ella no esté. No puede decirle a nadie que su hermana va a ir a buscarla y que no quiere ir con ella, que no quiere, no quiere (2019: 57).

Así termina el cuento, provocando, al mismo tiempo, la inquietud y la empatía del receptor ante la experiencia de esa niña acosada por el fantasma de su hermana, que se convierte también en emisaria de su muerte ${ }^{15}$.

\section{PARA CERRAR...}

Termino aquí este recorrido (incompleto) por algunas de las formas y sentidos que adquiere la monstruosidad femenina en la obra de las narradoras fantásticas españolas actuales. Dado el espacio disponible para llevar a cabo este trabajo, he optado, como dije al principio, por analizar algunas de las principales manifestaciones de lo monstruoso en

\footnotetext{
${ }^{15}$ Para no hacer aún más largo este trabajo, dejo fuera de mi análisis otros muchos cuentos que exploran la figura de la niña monstruo, como ocurre, por ejemplo, con "La gemela fea" y "La niña obediente", de Patricia Esteban Erlés (2012), y "La niña de tierra” y "Nekomata”, de Ángeles Mora (2020).
} 
el ámbito familiar, con la voluntad de demostrar, no solo la pervivencia y funcionalidad del monstruo en la ficción fantástica actual de autoría femenina, sino su reactualización y su empleo como vía de subversión de lo real (objetivo de toda ficción fantástica) y, sobre todo, para denunciar los condicionantes culturales, sociales y políticos impuestos sobre la mujer, específicamente en lo referido a la experiencia de la maternidad, las estructuras (y jerarquías) familiares y el mundo infantil.

\section{REFERENCIAS BIBLIOGRÁFICAS}

\section{OBRAS LITERARIAS}

CRespo, M. (2017). Las madres secretas. Barcelona: Editorial Base.

CRuZ, A. DE LA (2015). Modelos animales. Madrid: Salto de Páginas.

Esteban ERlÉs, P. (2012). Casa de muñecas. Madrid: Páginas de Espuma. (2019). Manderley en venta y otros cuentos. Madrid: Páginas de Espuma.

GonZÁlez-Pola, C. Y Del Toro, C., CoOrds. (2019). Monstruosas. Madrid: Tinta Púrpura Ediciones.

IWASAKI, F. (2004). Ajuar funerario. Madrid: Páginas de Espuma.

Martínez CAstiLlo, A. (2019). Reliquias. León: Eolas Ediciones.

MorA, Á. (2020). Somos juegos de cordel. Albacete: InLimbo Ediciones.

SAntos, C. (2009). Los que rugen. Madrid: Páginas de Espuma.

Solsona Asensio, G. (ED.) (2018). Vuelo de brujas. Madrid: Apache Libros.

Zaragoza, M. (2020). "El que murió sin perdón”. En Ars Moriendi. Cuentos de la no vida, G. Solsona Asensio (coord.), 81-91. Albacete: In Limbo Ediciones.

\section{ESTUDIOS}

Abalia, A. (2013). Lo siniestro femenino en la creación plástica contemporánea. Vitoria: Servicio Editorial de la Universidad del País Vasco.

Álvarez MÉndez, N. (2019). "Domestic Horror and Gender Conflicts in the Narratives of Patricia Esteban Erlés”. Bulletin of Hispanic Studies 96.6, 627-640.

Amaro CASTRO, L. (2020). "Maternidades 'líquidas': feminismos y narrativas recientes en Chile”. Revista Chilena de Literatura 101, 13-39. Disponible en línea: https://dx.doi.org/10.4067/S0718-22952020000100013 [10/01/2021].

ARnold, S. (2013). Maternal Horror Film: Melodrama and Motherhood. Londres: Palgrave MacMillan.

BADINTER, E. (1980). ¿Existe el amor maternal? Historia del amor maternal. Siglos XVIII al XX. Barcelona: Paidós. 
Balanzategui, J. (2018). "The Child is Uncanny Other". En The Uncanny Child in Transnational Cinema: Ghosts of Futurity at the Turn of the Twenty-First Century, J. Balanzategui (ed.), 9-31. Amsterdam: Amsterdam University Press.

BoccutI, A., ED. (2018). El humor y lo fantástico. Brumal. Revista de Investigación sobre lo Fantástico VI.1, 7-222.

Bohlman, M., \& S. Moreland, EdS. (2015). Monstrous Children and Childish Monsters: Essays on Cinema's Holy Terrors. Jefferson: McFarland.

Bornay, E. (1990). Las hijas de Lilith. Madrid: Cátedra.

Braidotti, R. (1994). Nomadic Subjects: Embodiment and Sexual Difference in Contemporary Feminist Theory. New York: Columbia University Press.

BÜSSING, S. (1987). Aliens in the Home: The Child in Horror Fiction. Westport: Greenwood Press.

Butler, J. (1993). Bodies That Matter: On the Discursive Limits of "Sex". London: Routledge.

CAMPRA, R. (1991). "Los silencios del texto en la literatura fantástica". En El relato fantástico en España e Hispanoamérica, E. Morillas Ventura (ed.), 49-73. Madrid: Sociedad Estatal Quinto Centenario-Editorial Siruela.

Carroll, N. (2005). Filosofía del terror o paradojas del corazón. Madrid: Antonio Machado Libros.

Cohen, J. J. (1996). "Monster Culture (Seven Theses)". En Monster Theory: Reading Culture, J. J. Cohen (ed.), 1-25. Minneapolis: University of Minnesota Press.

CORTÉS, J. M. G. (1997). Orden y caos. Un estudio cultural sobre lo monstruoso en el arte. Barcelona: Anagrama.

Creed, B. (1993). The Monstrous Feminine. Film, Feminism, Psychoanalysis. London: Routledge.

Dikstra, B. (1986). Idols of Perversity. Fantasies of Feminine Evil in Fin-de-Siècle Culture. New York: Oxford University Press.

Domínguez, N. (2007). De donde vienen los niños. Maternidad y escritura en la cultura argentina. Rosario: Beatriz Viterbo Editora.

DonAth, O. (2017). Madres arrepentidas. Una mirada radical a la maternidad y sus falacias sociales. Barcelona: Reservoir Books.

Eagleton, T. (2010). Sobre el mal. Barcelona: Península.

FEDERICI, S. (2010). Calibán y la bruja. Mujeres, cuerpo y acumulación originaria. Madrid: Traficantes de Sueños.

GonzÁlez DinAmarca, R. I. (2015). "Los niños monstruosos en El Orfanato de Juan Antonio Bayona y Distancia de rescate de Samanta Schweblin”. Brumal. Revista de Investigación sobre lo Fantástico III.2, 89-106.

Hock-SonN NG, A. (2004). Dimensions of Monstruosity in Contemporary Narratives. Theory, Psychoanalysis, Postmodernism. New York: Palgrave MacMillan.

Hollinger, V. (1997). "Fantasies of Absence: The Postmodern Vampire". En Blood Read: The Vampire as Metaphor in Contemporary Culture, Joan Gordon \& 
Veronica Hollinger (eds.), 199-212. Philadelphia: University of Pennsylvania Press.

HutCheOn, L. (1985). A Theory of Parody. Londres: Methuen.

(1988). A Poetics of Postmodernism: History, Theory and Fiction. London: Routledge.

IRIGARAY, L. (2007 [1974]). Espéculo de la otra mujer. Madrid: Akal.

KNIBIEHLER, Y. (2000). Histoire des mères et de la maternité en Occident. Paris: PUF.

Kord, T. S. (2016). Little Horrors: How Cinema's Evil Children Play on Our Guilt. Jefferson: McFarland.

KristeVA, J. (1988). Los poderes de la perversión. Buenos Aires: Siglo Veintiuno Editores.

La NAVE InVISIBLE (2018). "Prólogo". En Vuelo de brujas, G. Solsona Asensio (ed.), 1113. Madrid: Apache Libros.

LENNARD, D. (2015). Bad Seeds and Holy Terrors: The Child Villains of Horror Film. Albany: State University of New York Press.

LuRY, K. (2010). The Child in Film. Tears, Fears and Fairy Tales. Londres: Tauris.

Muchenbled, R. (2002). Historia del diablo. Siglos XII-XX. México: Fondo de Cultura Económica.

Noguerol JimÉnEZ, F. (2013). "Sacadas de quicio: maternidad y literatura en escritoras latinoamericanas contemporáneas". Review. Literature and Arts of the Americas 86, 46.1, 13-19.

Padilla, I. (2013). El legado de los monstruos. Tratado sobre el miedo y lo terrible. Madrid: Taurus.

PAlOMAR VereA, C. (2004). "Malas Madres: la construcción social de la maternidad". Debate Feminista 30, 12-34.

(2005). "Maternidad: historia y cultura". La Ventana 22, 35-67.

PEDRAZA, P. (1991). La bella, enigma y pesadilla. Barcelona: Tusquets.

(1998). Máquinas de amar: Secretos del cuerpo artificial. Madrid: Valdemar.

(2004). Espectra: Descenso a las criptas de la literatura y el cine. Madrid: Valdemar.

(2014). Brujas, sapos y aquelarres. Madrid: Valdemar.

Recalcati, M. (2018). Las manos de la madre. Deseo, fantasmas y herencia de lo materno. Barcelona: Anagrama.

Renner, K., ED. (2013). The "Evil Child" in Literature, Film and Popular Culture. Nueva York: Routledge.

(2015). "Monstrous Newborns and the Mothers Who Love Them: Intensive Mothering in Twenty-First-Century Horror Films". En Monstrous Children and Childish Monsters: Essays on Cinema's Holy Terrors, S. Moreland \& M. Bohlman (eds.), 27-41. Jefferson: McFarland. (2016). Evil Children in the Popular Imagination. New York: Palgrave Macmillan.

(C) UNED. Revista Signa 31 (2022), pp. 105-124 
Rich, A. (1976). Of Woman Born. Motherhood as Experience and Institution. New York: WW Norton.

RoAs, D. (2011). Tras los límites de lo real. Una definición de lo fantástico. Madrid: Páginas de Espuma.

(2014). "Mutaciones del cuento fantástico: la ironía y la parodia como subversión de lo real". En Mutações do Conto nas Sociedades Contemporâneas, E. Keating et al. (coords.), 23-36. Braga: Universidade do Minho.

(2019). "El monstruo fantástico posmoderno: entre la anomalía y la domesticación". Revista de Literatura LXXXI.161, 29-56.

(2020). "Fantástico femenino vs. Fantástico feminista. Género y transgresión de lo real". En Las creadoras ante lo fantástico. Visiones desde la narrativa, el cine y el cómic, D. Roas y A. Massoni (eds.), 15-29. Madrid: Visor Libros.

SANGRE FuCsia (2019). "Nosotras somos las monstruas". En Monstruosas, Covadonda González-Pola y Cristina del Toro (coords.), 9-13. Madrid: Tinta Púrpura Ediciones.

SAntos, C. (2016). Unbecoming Female Monsters: Witches, Vampires, and Virgins. Lanham: Lexington Books.

USSHER, JANE M. (2006). Managing the Monstrous-Feminine: Regulating the Reproductive Body. Londres: Routledge.

VARga Llamazares, R. DE la (2015). "Mujeres que matan. Dimensiones del monstruo en la narrativa de Patricia Esteban Erlés". En Espejismos de la realidad: percepciones de lo insólito en la literatura española (siglos XIX-XXI), N. Álvarez y A. Abello (eds.), 233-242. León: Servicio de Publicaciones de la Universidad de León.

Fecha de recepción: 11/01/2021

Fecha de aceptación: 03/03/2021 